\title{
STRESS-STRAIN BEHAVIOR OF NORMAL AND HIGH-STRENGTH STEEL-FIBER CONCRETE POST BURNING
}

\author{
Purwanto $^{1,2, *}$, Antonius ${ }^{3}$, and Prabowo Setiyawan ${ }^{4}$ \\ ${ }^{1}$ Doctoral Candidate of Civil Engineering, Universitas Islam Sultan Agung, Indonesia \\ ${ }^{2}$ Lecturer of Civil Engineering, Universitas Semarang, Indonesia \\ ${ }^{3}$ Professor of Civil Engineering, Universitas Islam Sultan Agung, Indonesia \\ ${ }^{4}$ Associate Professor of Civil Engineering, Universitas Islam Sultan Agung, Indonesia \\ *Corresponding Author, Received: 21 May 2021， Revised: 14 July 2021, Accepted: 26 July 2021
}

\begin{abstract}
This paper presents the results of experimental testing on steel fibrous concrete cylinder specimens after being burned for a certain period of time. The purpose of this research is to explore and develop an analytical expression on the stress-strain behavior of steel-fiber concrete by considering various variables. Precisely, the variables reviewed are the compressive strength of concrete which is defined as concrete with normal-strength, medium-strength and high-strength; the volume of fiber fraction in the concrete, namely $0 \%$, $1 \%$ and 2\%; and burning time for 1 hour, 2 hours and 3 hours. All cylindrical specimens measuring $100 \times 200$ $\mathrm{mm}$ were tested against uniaxial loads. The experimental results showed that all the fiber-free specimens had experienced a decrease in strength with increasing firing time. Normal-strength concrete specimens lose strength by $30-35 \%$ after burning for 1 hour or 2 hours, and the strength degradation increases to $60 \%$ at 3 hours after burning. Medium-strength concrete specimens lost $10 \%$ strength after being burned for 1 hour , then lost 30\% and $60 \%$ strength after 2 hours and 3 hours of burning, respectively. High-strength concrete specimens lose $10 \%$ strength if burned for 1 hour, then the strength is lost $20 \%$ and $55 \%$ after burning 2 hours and 3 hours, respectively. Another result is a trend of increasing peak strain of concrete with increasing burning time. In this paper, an analytical expression of stress-strain post-burning steel-fibrous concrete is developed. The comparison results show that the analytical expression is able to predict the experimental results of normal and high-strength steel-fiber concrete with various variations in the volume of the steel fiber fraction effectively.
\end{abstract}

Keywords: Stress, Strain, Steel fiber, Volume fraction, Burning time

\section{INTRODUCTION}

Fibrous concrete is known to be one of the smart materials because it has several advantages of its characteristics such as matrix bonding and better ductility compared to plain concrete [1-3]. The addition of fiber to concrete can significantly increase ductility and is valuable in its use in building structures in strong earthquake areas. The combination of steel fibers with concrete, even in high-strength concrete, will be one of the solutions to significantly reduce the need for reinforcement installed in structures [4].

The characteristics of fibrous concrete including constitutive models are currently still being developed [5-8]. Based on the results of these studies, it was revealed that the addition of fiber was able to increase the strength of the concrete material. Lee et al [9] examined the mechanical behavior of steel-fibrous concrete but utilized a particular type of fiber, namely end-hooked. Structurally, the flexural behavior of fibrous concrete has also been investigated [10,11].

Steel fibers substituted into concrete mixtures are reasonably popular because they are tolerant to obtain and form. Steel-fiber concrete is exceptionally sensitive to temperature, especially at high temperatures, compared to normal concrete (without fibers). The content of steel in the concrete is a leading factor affecting the mechanical behavior (like compressive strength) of concrete. In the case of civil buildings experiencing fires for various reasons, the fires that occur can take hours or a long time and can reach temperatures of $900^{\circ} \mathrm{C}$ or even more, so it is necessary to investigate steel-fibrous concrete when it is at very high temperatures. Until now, the constitutive model of post-burn concrete is still dominated by plain concrete material which is burned to a high temperature [12,13]. CEB-FIP in Model code 2010 [14] has also modeled plain concrete at high temperatures. CEB-FIP examines post-burn plain concrete in the temperature domain and also converts it to burning time for example in 60 minutes, 120 minutes and 180 minutes.

The mechanical behavior of fibrous concrete after burning up to a temperature of $900^{\circ} \mathrm{C}$ by Antonius et al [15] and Purwanto et al [16] proposes a constitutive equation for mechanical behavior but is however limited to the volume of the fiber fraction of 0.5\%. Bezerra et al [17] and Chen et al 
[18] investigated the mechanical behavior of steelfibrous concrete at high temperatures where the burning temperature reached $500^{\circ} \mathrm{C}$. On the other hand, an analysis simulation of fibrous concrete based on a numerical method that was validated against experimental results and revealed that postburn fibrous concrete tends to experience a trend of decreasing strength but its ductility increases if the temperature applied is more excessive [19]. Furthermore, Bezerra et al [17] and Zhang et al [20] reveal the residual strength of steel-fibrous concrete at various temperatures is more superior than the residual strength of plain concrete. In addition, steel fibers play a role both in increasing fire resistance and preventing explosive peeling of the concrete (spall) when the fibrous concrete is burned at high temperatures. Zaidi et al [21] and Korsun et al [22] started researching the post-burning fibrous concrete and they had succeeded in developing a model of confined fibrous concrete at elevated temperatures. Antonius et al [23], Kim et al [24] also studied the ductility behavior of steel-fibrous concrete beams at various temperatures, and it was concluded that the ductility of the structure decreased compared to the ductility of the structure without being burned, but the decrease in the ductility value was insignificant. In other structural fields, the post-combustible shears ability of steelfibrous concrete has also been studied [25-27]. Cheng et al [28] and Santos et al [29] derive stressstrain models for post-burn plain concrete and postburn fibrous concrete, respectively, where these models review the burning of specimens based on temperature.

This research was conducted on post-burn steel fibrous concrete by varying the duration of burning $(t)$, namely 0 hour or specimens were unburned, burned 1 hour, 2 hours and 3 hours. Other variables are the compressive strength of concrete $\left(f^{\prime} c\right)$, volume fraction of fiber $\left(V_{f}\right)$, namely $0 \%$ as control specimens of fibrous concrete, $1 \%$ and $2 \%$. The fundamental objective of this research is to obtain comprehensive information regarding the strength loss, ductility, and stress-strain behavior of post-fire materials. Based on the experimental results, an analytical expression of stress-strain behavior will be developed.

\section{RESEARCH SIGNIFICANT}

In general, concrete after burning will raise questions about whether the concrete is still suitable for use as a structural material. On the other hand, the post-burn fibrous concrete design standard was unregulated by the Indonesian concrete code [30]. Therefore, in-depth research is required on the capacity of these structures to ensure the safety level of the post-burn fibrous concrete. The analytical expression of stress-strain is needed as a basic reference in carrying out a post fire fibrous crosssection analysis of concrete. Equations of strength degradation, changes in strain and ductility are needed in calculating the strength of the post-burn fibrous concrete.

\section{EXPERIMENTAL PROGRAM}

\subsection{Materials}

Manufacture of fibrous and nonfiber concrete specimens utilizing commercially available materials. The compressive strength of concrete is designed into three groups of water-cement ratios $(w / c)$, namely $0.53,0.38$ and 0.28 . Each w/c group is the calculation result to obtain concrete with normal compressive strength $\left(f_{c}^{\prime} \sim 30 \mathrm{MPa}\right)$, medium compressive strength $\left(f_{c}^{\prime} \sim 50 \mathrm{MPa}\right)$ and high compressive strength $\left(f_{c}^{\prime} \sim 70 \mathrm{MPa}\right)$. The mix design procedure is based on SNI-7656-2012 [31]. The design of the concrete mixture is presented in Table 1. To maintain the workability of the concrete, Viscocrete is added at a dose of $0.5 \%$ by weight of cement.

Table 1 Concrete mix design

Materials $\quad w / c=0.53 \mathrm{w} / \mathrm{c}=0.38 \mathrm{w} / \mathrm{c}=0.28$

\begin{tabular}{|c|c|c|c|c|}
\hline \multicolumn{2}{|c|}{ Cement $\left(\mathrm{kg} / \mathrm{m}^{3}\right)$} & 350 & 420 & 485 \\
\hline \multicolumn{2}{|c|}{ Fly Ash $\left(\mathrm{kg} / \mathrm{m}^{3}\right)$} & - & 72 & 828 \\
\hline \multicolumn{2}{|c|}{ Water $\left(\mathrm{lt} / \mathrm{m}^{3}\right)$} & 186 & 160 & 136 \\
\hline \multicolumn{2}{|c|}{ Sand $\left(\mathrm{kg} / \mathrm{m}^{3}\right)$} & 723 & 464.6 & 622 \\
\hline \multicolumn{2}{|c|}{$\begin{array}{l}\text { Coarse aggregate } \\
\left(\mathrm{kg} / \mathrm{m}^{3}\right)\end{array}$} & 886.8 & 1045 & 1086 \\
\hline \multicolumn{2}{|c|}{ Viscocrete $\left(\mathrm{kg} / \mathrm{m}^{3}\right)$} & 1.75 & 7.38 & 10.7 \\
\hline \multirow{3}{*}{$\begin{array}{l}\text { Steel fiber } \\
\left(\mathrm{kg} / \mathrm{m}^{3}\right)\end{array}$} & $V_{f}=0 \%$ & - & - & - \\
\hline & $V_{f}=1 \%$ & 21.5 & 24 & 24.6 \\
\hline & $V_{f}=2 \%$ & 42.9 & 48 & 49 \\
\hline
\end{tabular}

The steel fibers employed are presented in Fig.1. The steel fibers were purchased in the market and are in the form of wire frequently used as a steel reinforcement for reinforced concrete components. In this study, the ratio of fiber length to diameter was determined between 40-50 values.

\subsection{Specimens, Instrumentation and Testing}

The specimen in this study is a cylinder with a diameter of $100 \mathrm{~mm}$ and a height of $200 \mathrm{~mm}$. The specimens being cast are then cured by covering the specimens with wet sacks. The burning of the specimens follows the ASTM C 39-94 [32] procedure, namely after the specimens are 90 days old from casting. Fig.2 represents the process of arranging and burning the test object. 


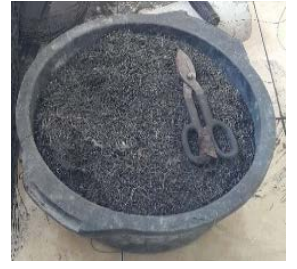

Fig.1 Steel fibers
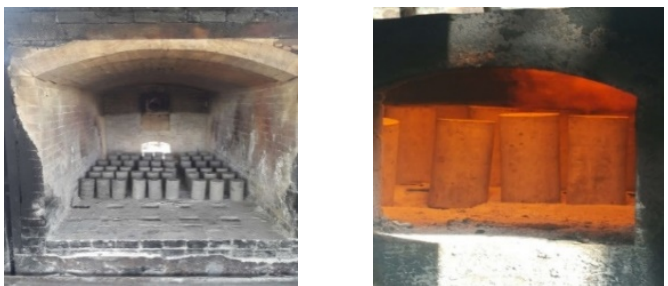

Fig. 2 The process of preparation and burning of test specimens

Commonly, the incident of frequent-building fire is caused by long duration of burning. According to ASTM E 119-00a, the duration of burning in the material test for 1 hour, 2 hours and 3 hours can be converted into temperatures of $927^{\circ} \mathrm{C}$, $1010^{\circ} \mathrm{C}$ and $1052^{\circ} \mathrm{C}$, respectively. Therefore the temperature imposed on the specimen is all above $900^{\circ} \mathrm{C}$ or high temperature.

The process of burning the specimens begins with the arrangement of the specimens and then continued with 1 hour of burning. After that the specimens were removed from the furnace to be replaced with other specimens and burned for 2 hours. The same process was also carried out for burning the specimen for 3 hours.

After burning the specimens, preparations are required before carrying out the compressive test. The specimens were fitted with a strain gauge type PFL-30-11 to measure the axial strain of the concrete. LVDT is installed on two sides of the cross section to measure the deflection of the specimen in axial direction.

Testing using the Universal Testing Machine with a capacity of $2000 \mathrm{kN}$ with a deformation control testing system. Press testing follows ASTM standards. The loading process starts from zero load, increasing slowly. While the load increases, the specimen surface is observed to determine the spalling process, cracks and specimen collapse. The stress occuring on the specimen is calculated by dividing the load obtained from the test reading divided by the cross-sectional area of the specimen.

\subsection{Toughness}

In this study, the ductility of the specimen is expressed in terms of toughness or energy that the specimen can absorb against uniaxial compressive loads. Toughness is expressed in Toughness Index (TI), where the calculation is based on the approach by Antonius [4] and Aoude et al [33] as showed in Fig.3. Based on this figure, TI is defined as the shaded area divided by the OABC rectangular area.

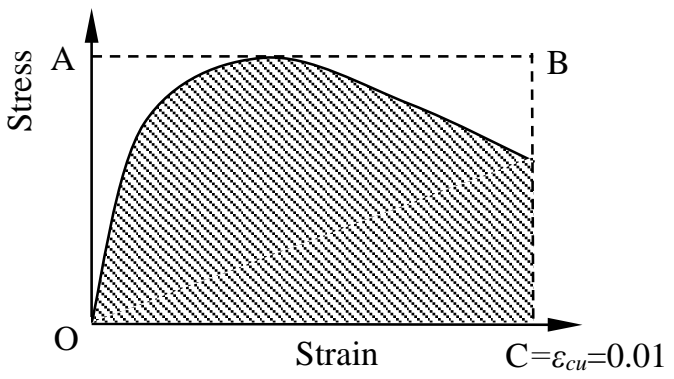

Fig.3 Analysis method of TI calculation

\section{EXPERIMENTAL RESULTS AND DISCUSSION}

The mix design carried out by varying the ratio of water to cement produces three varying types of compressive strength for 28-day-old concrete, namely the compressive strength of 34.9 MPa, 50.6 $\mathrm{MPa}$ and $70.5 \mathrm{MPa}$. Each of these compressive strengths is then grouped and called NormalStrength Concrete or (NSC), Middle-Strength Concrete (MSC) and High-Strength Concrete or abbreviated as HSC. The results of the experimental processing are presented in Table 2.

The failure mode of burnt steel-fiber concrete specimens with a duration of 1 hour, 2 hours or 3 hours generally indicates that steel-fiber concrete inexperience a sudden drop and is relatively ductile. This is opposed from the mode of collapse of fiberfree concrete $\left(V_{f}=0 \%\right)$ where visually the specimen can be said to collapse brittle. This behavior demonstrates the role of steel fibers in increasing the ductility of the material. The mode sample of collapse of the post-burn fibrous concrete specimen is shown in Fig.4, where the specimens consist of NSC, MSC and HSC with variations in fiber fractions of $0 \%, 1 \%$ and $2 \%$ (see Fig.4).

\subsection{Peak -Stress Degradation}

Evaluation of the decrease in the peak stress of the concrete to the duration of burning is carried out by normalizing the peak stress in each specimen in Table 2 above on the compressive strength of the control concrete. All NSC specimens, both without fiber and containing $1 \%$ and $2 \%$ steel fiber, experienced a trend of decreasing strength which was not much exceptional from one another (Fig.5). Burning the specimen for 1 hour can reduce the peak stress by about 25-35\%, When burned for 2 hours, the peak stress loss increases to $30-40 \%$. The loss of peak stress in concrete increases significantly to about $55-60 \%$ if the burning duration of the specimens reaches 3 hours. 
Table 2 Experimental results

\begin{tabular}{|c|c|c|c|c|c|c|c|c|c|c|c|c|c|}
\hline \multirow{3}{*}{$\begin{array}{l}\text { Concrete } \\
\text { strength, } \\
f^{\prime}{ }^{\prime}(\mathrm{MPa})\end{array}$} & \multirow{3}{*}{$\begin{array}{c}V_{f} \\
(\%)\end{array}$} & \multicolumn{12}{|c|}{ Peak strain, compressive strength and toughness index } \\
\hline & & \multicolumn{3}{|c|}{ Not burned } & \multicolumn{3}{|c|}{ Burned $1 \mathrm{~h}$} & \multicolumn{3}{|c|}{ Burned $2 \mathrm{~h}$} & \multicolumn{3}{|c|}{ Burned $3 \mathrm{~h}$} \\
\hline & & $\varepsilon_{c}^{\prime}{ }_{c}$ & $f_{c}$ & $\mathrm{TI}$ & $\varepsilon_{c t}^{\prime}$ & $f_{c t}$ & $\mathrm{TI}$ & $\varepsilon_{c t}^{\prime}$ & $f_{c t}$ & $\mathrm{TI}$ & $\varepsilon_{c t}^{\prime}$ & $f_{c t}$ & $\mathrm{TI}$ \\
\hline \multirow{3}{*}{$\begin{array}{c}\text { NSC } \\
34.9 \mathrm{MPa}\end{array}$} & 0 & & & & & 26.3 & & & & & & 15.9 & \\
\hline & & & & & & & & & & & & & \\
\hline & & & & & & & & & & & & & \\
\hline \multirow{3}{*}{$\begin{array}{c}\text { MSC } \\
50.6 \mathrm{MPa}\end{array}$} & 0 & & 50 & & & & & & & & & 18.3 & \\
\hline & 1 & & 57 & 0.8 & & 2.6 & & & 37.2 & & & 25 & \\
\hline & 2 & & 57. & & & 2.3 & & & 40 & & & 26.6 & \\
\hline \multirow{3}{*}{$\begin{array}{c}\text { HSC } \\
70.5 \mathrm{MPa}\end{array}$} & $\underline{0}$ & & 70.5 & 0.67 & & 62.1 & & & 55.4 & & & 33 & 66 \\
\hline & 1 & & 71.1 & 0.75 & & 69.6 & & & 58.4 & & & 33.6 & \\
\hline & 2 & 0.0067 & 80.6 & 0.80 & 0.007 & 70.7 & 0.78 & 0.0073 & 62.1 & 0.82 & 0.008 & 39.6 & U. $1 / 1$ \\
\hline
\end{tabular}

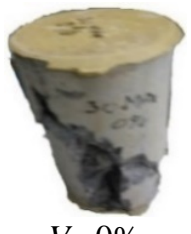

$V_{f}=0 \%$

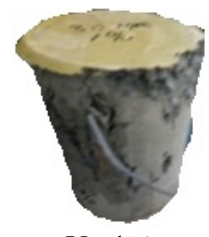

$V_{f}=1 \%$

a) Specimens of NSC

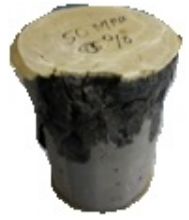

$V_{f}=0 \%$

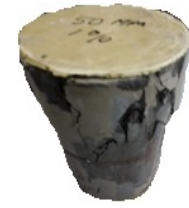

$V_{f}=1 \%$

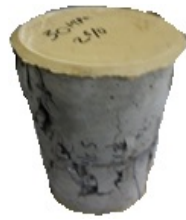

$V_{f}=2 \%$ b) Specimens of MSC

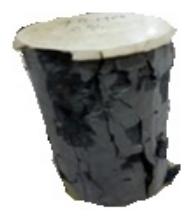

$V_{f}=0 \%$

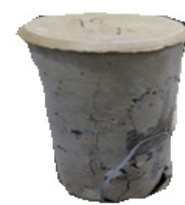

$V_{f}=1 \%$

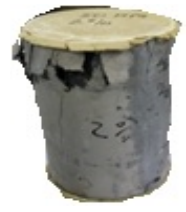

$V_{f}=2 \%$ c) Specimens of HSC

Fig.4 Samples of failure modes of specimens post burning

The strength degradation behavior is slightly different in the MSC specimens. All specimens only lose a maximum peak stress of $10 \%$ if the specimen's burning process takes place only 1 hour. However, when the specimen was burned for 2 hours, the peak stress loss was the same as that of the NSC specimen above, which was between 30$40 \%$. Likewise, if the specimen is burned for 3 hours, the peak stress loss is about $55-60 \%$ or the same as the peak stress loss of the MSC specimen above except for the fiberless specimen $\left(V_{f}=0 \%\right)$.

In case of HSC, burning the specimen for one hour resulted in the specimen losing about $10-15 \%$ of stress, except for specimens with a volume fraction of $1 \%$ fiber which lost relatively little strength (less than 5\%). The specimen burned for 2 hours causes a peak stress loss of $20 \%$ and if the specimen is burned for 3 hours the peak stress loss is about $45 \%$. These results indicate that in highstrength concrete (HSC), the loss of strength after burning 1, 2 and 3 hours is less than burning with the same duration in NSC and MSC.

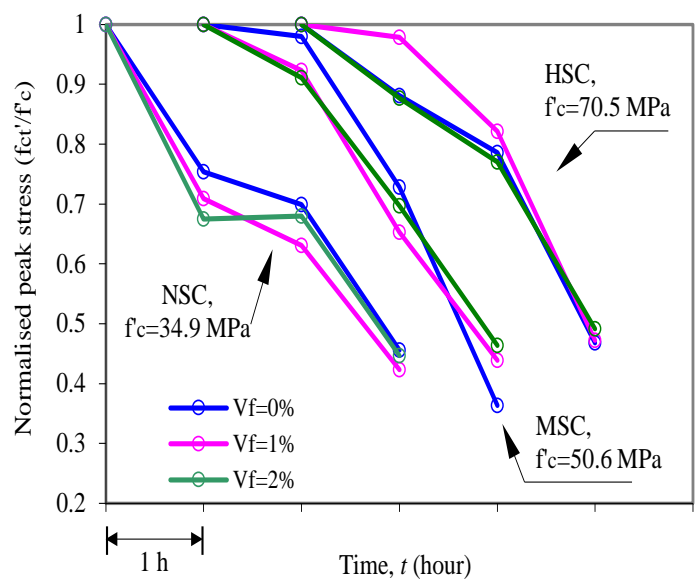

Fig.5 Degradation of strength to duration of burning

\subsection{Peak Strain After Burning}

In general, based on Table 2 it can be said that all the peak strain of the unburned and burned concrete specimens $\left(\varepsilon_{c}^{\prime}\right.$ and $\left.\varepsilon_{c t}^{\prime}\right)$ has increased with increasing burning time. This is also shown in Fig.6. Based on the data in Table 2 and from the three figures, the increase in peak strain from a 2-hour burning time to the lowest of a 3-hour burning occurs in fiber-free specimens (plain concrete).

This behavior especially in fibrous concrete indicates that although the concrete experiences a loss of strength when burned with an increasing duration, it can experience significant deformation due to the role of steel fibers. This also shows the steel-fiber concrete specimens are ductile. 


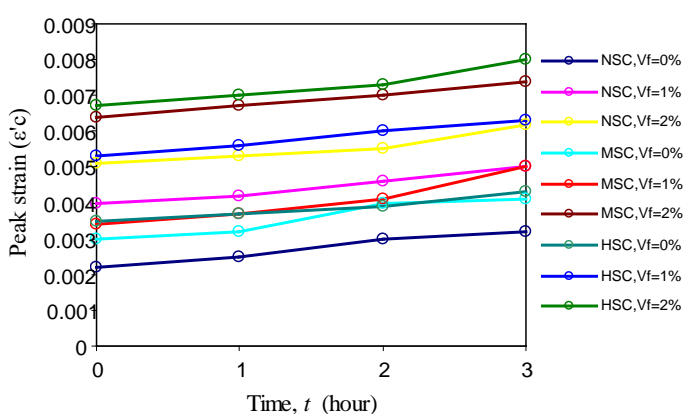

Fig.6 Increased strain with respect to burning time

\subsection{Toughness}

The experimental results show that the $T I$ value increases linearly with the increasing volume of fiber fraction in each concrete compressive strength group and the specimens are burned at the same temperature. These results are in line with the fundamental theory of fibrous concrete that fibers play a significant role in increasing the energy that the specimen can absorb, or in other words, the higher the fiber contained in the concrete, the more ductile the material is.

On the other hand, the experimental results show that the $T I$ value does not always increases in case that the burning duration is longer. For example, in a fiber-free NSC specimen, when it was unburned it contained a $T I$ value of 0.48 , but after burning for 1 hour the $T I$ value decreased to 0.41 , then after being burned for 2 hours and 3 hours the TI value increased to 0.43 and 0.49 respectively. Likewise in the NSC specimen with a volume fraction of $1 \%$ fiber, where the TI value that was unburned was 0.81 , then the TI value decreased to 0.67 and 0.59 at 1 hour and 2 hours of burning, but the TI value again increased to 0.75 if the specimen was burned 3 hour. Similar behavior is also shown in HSC specimens, for example specimens with a volume fraction of $2 \%$ fiber. If the specimen is unburned, the TI value is 0.80 , then if it is burned for 1,2 and 3 hours, the TI value will be $0.78,0.82$ and 0.77 , respectively.

During the specimen burning, there are specimens undergoing rapid or slower spalling and unaffected by the duration of the burning. It can be identified that the occurring residual stress is different and uncertain for each specimen. This behavior will be recognized in the stress-strain curve, therefore the area of the stress-strain behavior is also highly variable. This implies the duration of burning has neither effect nor the determination of the amount of residual stress.

\subsection{Stress-strain Behavior}

Stress-strain behavior analysis of all specimens was performed to evaluate the behavior of the specimens before and after peak stresses. The stress behavior is described by normalizing the stress on the compressive strength of the concrete.

\subsubsection{Specimens without burning}

The stress-strain behavior of the unburned specimens which function as control specimens is shown in Fig.7. In general, fiber-free specimens show post-peak stress behavior which tends to be brittle when the compressive strength of the concrete increases. The presence of steel fibers in the concrete plays a role in increasing ductility, which is indicated by the relatively sloping postpeak behavior compared to the fiber-free specimens.

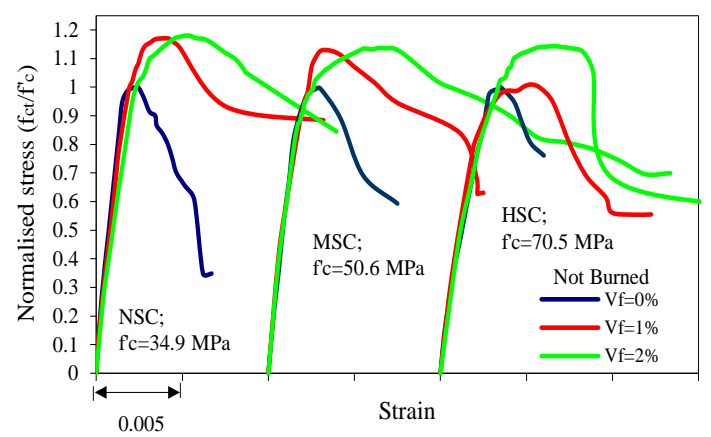

Fig.7 Effect of fibers on unburned specimens

\subsubsection{Effect of burning duration}

Fig.8 to Fig.10 show the stress-strain behavior of the specimens in view of the variable duration of burning. As explained above, the peak strain of concrete increases. The increase in the peak strain of concrete was noted significantly in the $1 \%$ fibrous concrete specimen even in the $2 \%$ volume fraction specimen. As shown in Fig.12, where the concrete without fiber $\left(V_{f}=0 \%\right)$, shows the peak strain and post-peak behavior which is more sloping as the duration of specimen burning is longer. However, if the specimen contains $1 \%$ fiber, in addition to the higher the peak strain of the concrete, the post-peak concrete response looks more sloping if the specimen is burned longer. This behavior is shown in Fig.13. A more significant behavior in the ductility of the concrete with the increasing duration of burning is shown in Fig.14 where the concrete specimen contains a volume fraction of $2 \%$ fiber. 


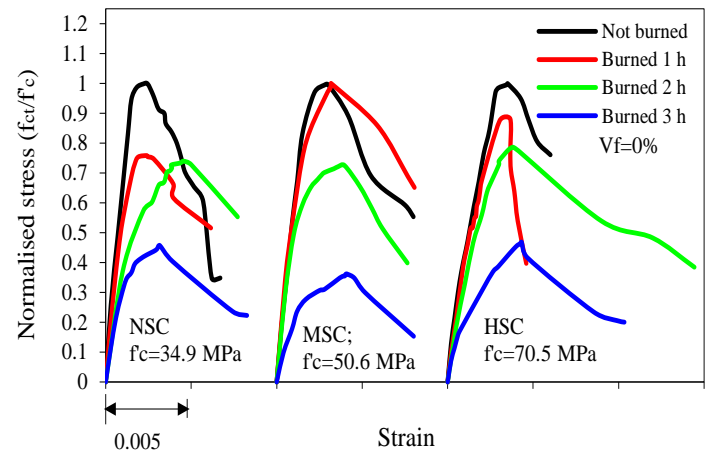

Fig.8 Effect of duration of burning for $V_{f}=0 \%$ (without fiber)

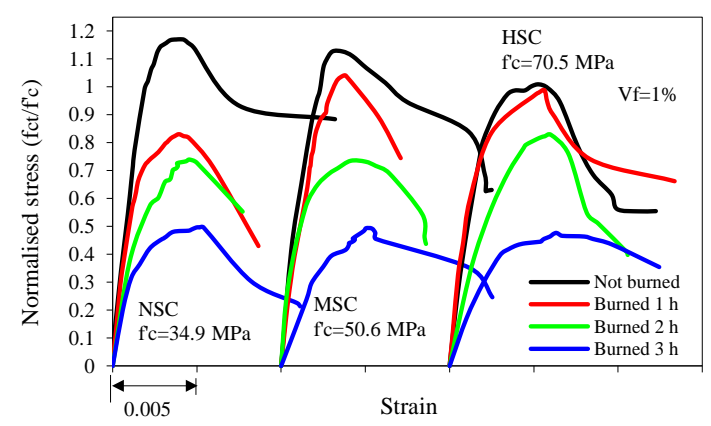

Fig.9 Effect of the duration of burning for $V_{f}=1 \%$

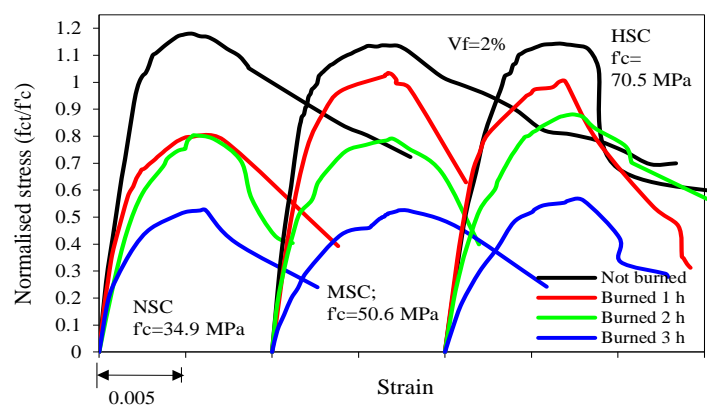

Fig.10 Effect of duration of burning for $V_{f}=2 \%$

\subsubsection{Effect of volume of fraction under burning}

The role of steel fibers in increasing the stress and ductility of normal-strength concrete to highstrength is shown in Fig.11 to Fig.13. At each firing duration of 1 hour, 2 hours and 3 hours, all specimens tended to be more ductile if the steel fibers used were higher. This is an indication of the role of steel fibers in maintaining the strength and ductility of concrete so as not to experience brittle collapse.

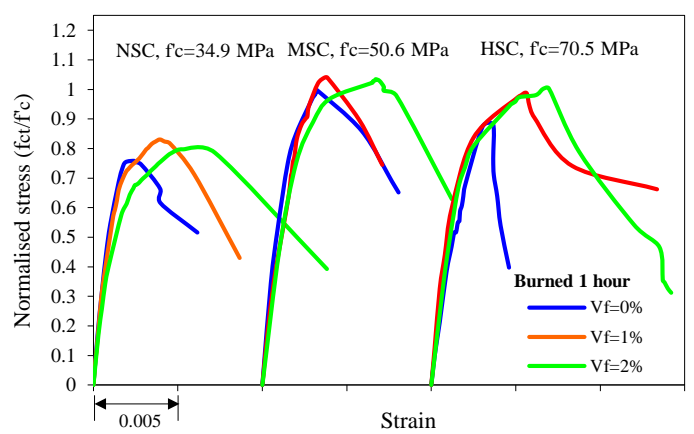

Fig.11 Effect of fiber on an-hour burning

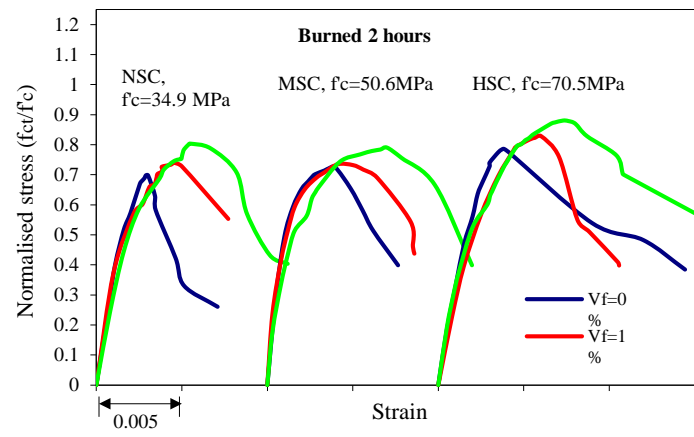

Fig.12 Effect of fiber on a-2 hour burning

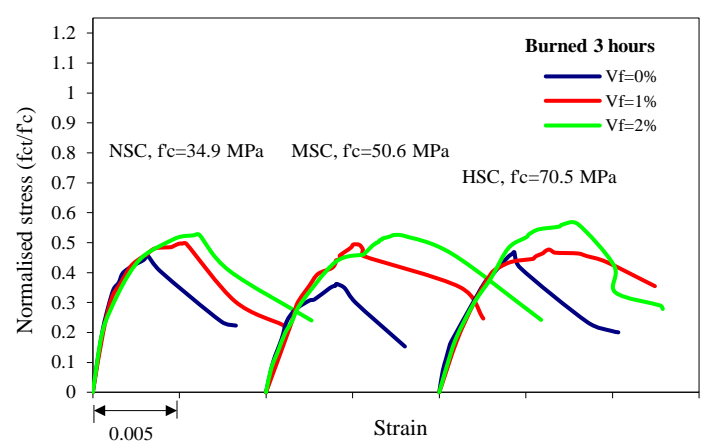

Fig.13 Effect of fiber on a -3 hour burning

\section{ANALYTICAL EXPRESSION TO ESTIMATE BEHAVIOR \\ THE STRESS-STRAIN}

\subsection{Stress-Strain Curves}

By this time the stress-strain equation for fibrous concrete has been proposed [15,20,28,34]. As a basis, the stress-strain equation in concrete generally adopts the model proposed by Nataraja et al [35], namely: 


$$
\frac{f_{c}}{f_{c f}^{\prime}}=\frac{\beta\left(\frac{\varepsilon_{c}}{\varepsilon_{o f}}\right)}{\beta-1+\left(\frac{\varepsilon_{c}}{\varepsilon_{o f}}\right)^{\beta}}
$$

Where $\beta$ is the factor that affects the shape of the post-peak curve. If the concrete contains no fibers, factor $\beta$ adopts the equation of Junior et al. (2010), namely:

$$
\beta=\left(0.0536-0.5754 V_{f}\right) f_{c}^{\prime}
$$

Where $V_{f}$ is the volume of the fiber fraction. If the concrete contains fiber, factor $\beta$ adopts the proposed equation by Nataraja (1999) as follows:

$$
\beta=0.5811+1.93(R I)^{-0,7406}
$$

Where $R I$ is the reinforcing index, namely the weight of the volume fraction multiplied by the ratio of the length of the steel fiber to its diameter $(l / d)$. The weight of the volume fraction $\left(\mathrm{w}_{\mathrm{f}}\right)$ is 3.2 times the volume of the fraction, so:

$$
R I=3.2 V_{f}(l / d)
$$

In this study, the average $l / d$ value is 45 . So that for $V_{f}=1 \%$ the value of $R I=(3.2)(0.01)(45)=1.44$, and for $V_{f}=2 \%$ the value of $R I$ is 2.88 .

The equation for the peak stress and peak strain of concrete due to the addition of steel fibers is:

$$
\begin{gathered}
f_{c f}^{\prime}={f_{c}^{\prime}}_{c}+2.1604(R I) \\
\varepsilon_{o f}^{\prime}=\varepsilon_{o}^{\prime}+0.0006(R I)
\end{gathered}
$$

Equations (5) and (6) above apply to the conditions without being burned or after being burned, where $f_{c}^{\prime}$ and $\varepsilon_{o}^{\prime}$ are taken based on the compressive strength of the concrete without fibers $\left(V_{f}=0 \%\right)$. Based on Antonius et al., 2017, the peak strain of concrete without fibers represent a function of the compressive strength of the concrete, namely:

$$
\varepsilon_{o}^{\prime}=0.0004\left(f_{c}^{\prime}\right)^{0,45}
$$

Based on the experimental results described above, the peak stress of the concrete decreased with the addition of the duration of burning, but on the other hand, the peak strain of the concrete increased with the increase in burning time. Therefore, the equation of the relationship between stress and stress on the duration of burning is derived based on the data of this study implementing linear regression.
For $V_{f}=0 \%$, the equation is:

$\left.\begin{array}{l}\frac{f^{\prime}{ }_{c t}}{f^{\prime}{ }_{c}}=1-0.1694 t \\ \frac{\varepsilon^{\prime}{ }_{c t}}{\varepsilon^{\prime}{ }_{c}}=1+0.1198 t\end{array}\right\}$

For $V_{f}=1 \%$ we get:

$\left.\begin{array}{l}\frac{f_{c t}^{\prime}}{f_{c f}^{\prime}}=1-0.1709 t \\ \frac{\varepsilon^{\prime}{ }_{c t}}{\varepsilon^{\prime}{ }_{o f}}=1+0.0928 t\end{array}\right\}$

For $V_{f}=2 \%$ the equation is:

$$
\begin{aligned}
& \frac{f_{c t}^{\prime}}{f_{c f}^{\prime}}=1-0.1676 t \\
& \frac{\varepsilon_{c t}^{\prime}}{\varepsilon^{\prime}{ }_{o f}}=1+0.056 t
\end{aligned}
$$

Where $f_{c t}$ ' and $\varepsilon_{c t}$ ' are peak stress and peak strain of concrete corresponding to the peak stress both at burning time.

\subsection{Comparison with Experimental Results}

Furthermore, the developed analytical expression of stress-strain above is compared with the experimental results presented in Fig.14 to Fig.22. The comparison results show that the analytical expression is able to effectively predict the stress-strain behavior before and after the peak, covering of normal and high-strength concrete with variations in the volume of fiber fraction and for each burning duration.

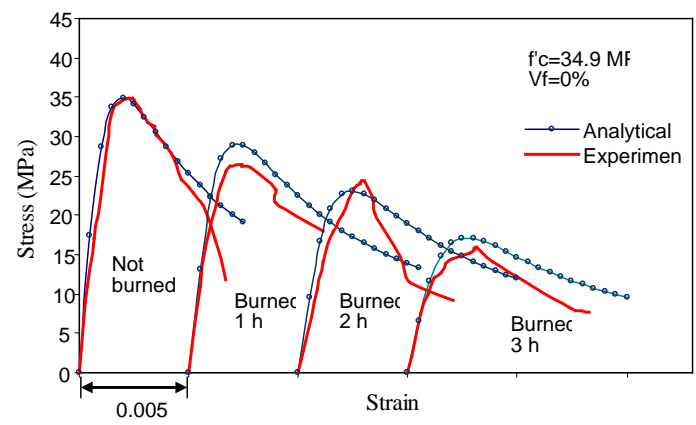

Fig.14 Analytical vs experiments for $f^{\prime}{ }_{c}=34.9 \mathrm{MPa}$, $V_{f}=0 \%$

\section{CONCLUSIONS}

Based on the research described above, some conclusions can be drawn are as follows:

Steel fibers consist of extremely superior added value, which is to increase the strength of the concrete as a result the cross-sectional capacity also increases. Another advantage is the deformability of steel-fiber concrete is equally higher. 


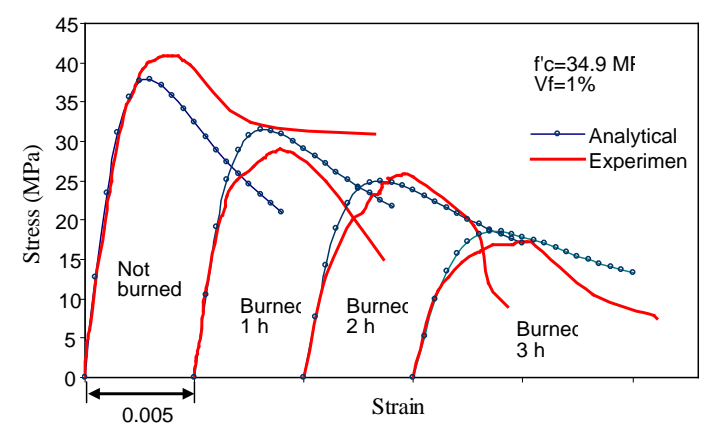

Fig.15 Analytical vs experiments for $f^{\prime}{ }_{c}=34.9 \mathrm{MPa}$, $V_{f}=1 \%$

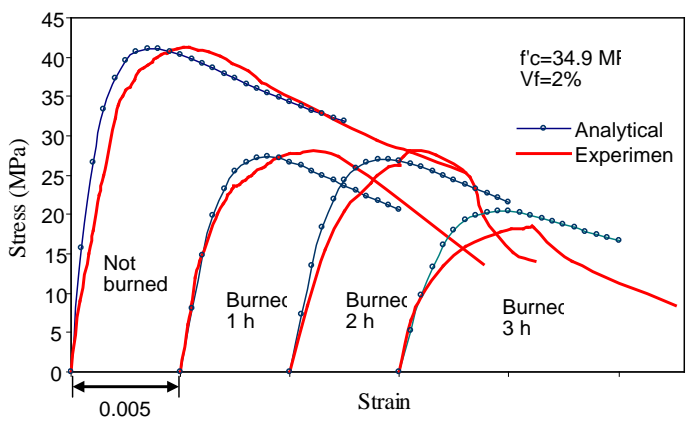

Fig.16 Analytical vs experiments for $f^{\prime}{ }_{c}=34.9 \mathrm{MPa}$, $V_{f}=2 \%$

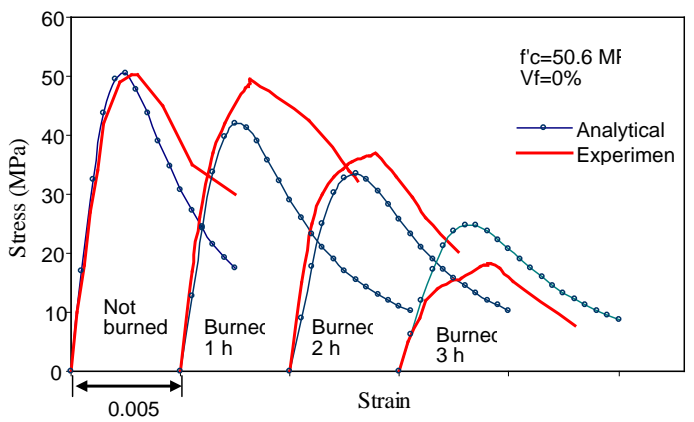

Fig.17 Analytical vs experiments for $f^{\prime}{ }^{\prime}=50.6 \mathrm{MPa}$, $V_{f}=0 \%$

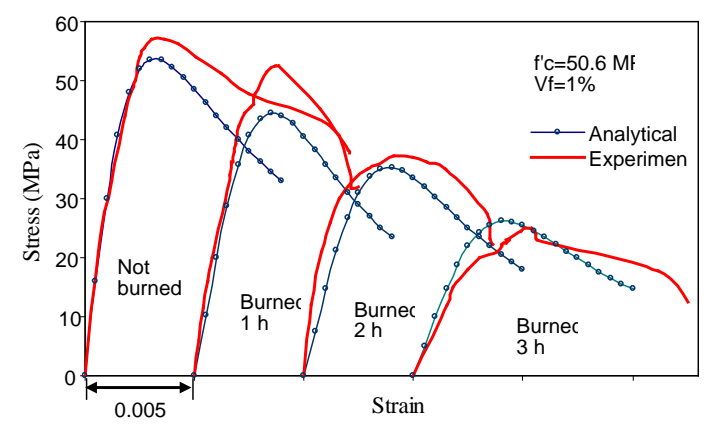

Fig.18 Analytical vs experiments for $f^{\prime}{ }_{c}=50.6 \mathrm{MPa}$, $V_{f}=1 \%$

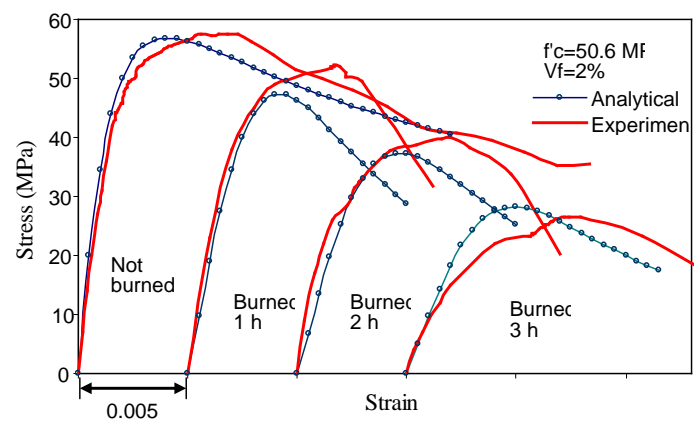

Fig.19 Analytical vs experiments for $f^{\prime}{ }_{c}=50.6 \mathrm{MPa}$, $V_{f}=2 \%$

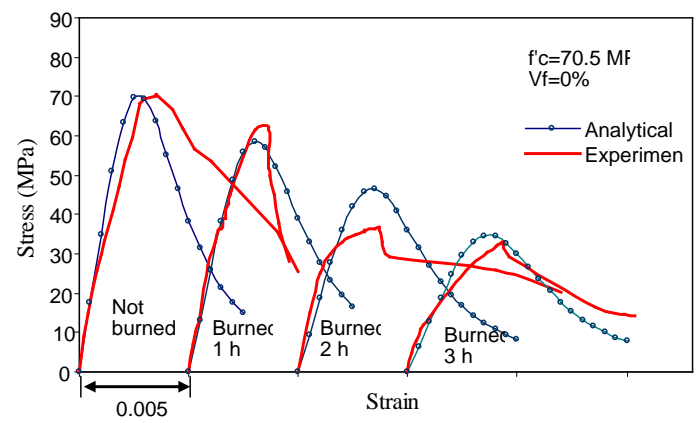

Fig.20 Analytical vs experiments for $f^{\prime}{ }_{c}=70.5 \mathrm{MPa}$, $V_{f}=0 \%$

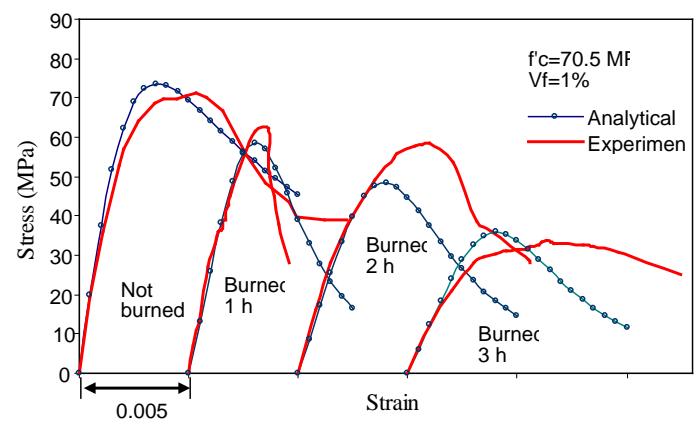

Fig.21 Analytical vs experiments for $f^{\prime}{ }_{c}=70.5 \mathrm{MPa}$, $V_{f}=1 \%$

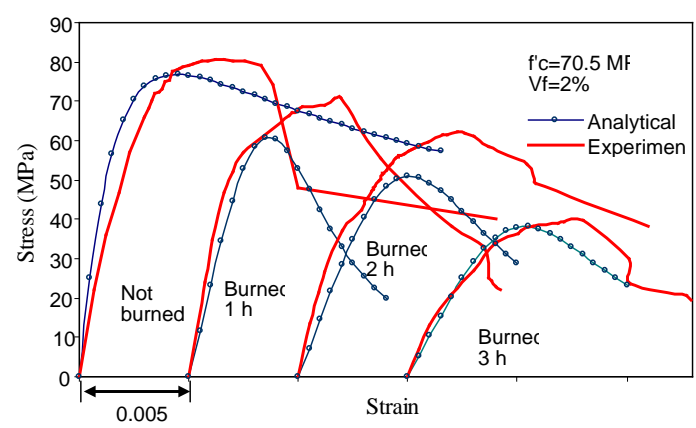

Fig.22 Analytical vs experiments for $f^{\prime}{ }_{c}=70.5 \mathrm{MPa}$, $V_{f}=2 \%$ 
In most cases, high-strength steel-fiber concrete $\left(f_{c}^{\prime}=70.5 \mathrm{MPa}\right)$ has the least strength degradation compared to the degradation of the strength of normal-strength fibrous concrete $\left(f_{c}^{\prime}=34.9 \mathrm{MPa}\right)$ and medium strength $\left(f_{c}^{\prime}=50.6 \mathrm{MPa}\right)$. This applies to specimens burned for 1 hour, 2 hours or 3 hours.

The peak strain of concrete experiences a significant increasing trend when burring duration is longer. In addition, the increase in the volume of fiber fraction equally affects the increase in the value of the strain.

The ability of the specimens to absorb energy expressed in the Toughness Index will increase significantly if the volume of the fiber fraction used increases. However, the TI value uncertainly increases even though the burning duration also increases or in other words the burning time experiences insignificant effect in determining the TI value.

The analytical expression of stress-strain developed in this study is able to predict the stressstrain behavior of steel-fiber concrete with variations in the volume fraction of the fiber and the duration of burning.

This study is still prime but useful among others in its use to determine the flexural capacity of steelfiber concrete after burning. In addition, this research can be developed on other structural elements like its shear capacity along with others.

\section{ACKNOWLEDGMENT}

Much appreciated to the Undip Alumni Foundation and Semarang University their providing financial support for the implementation of this research.

\section{REFERENCES}

[1] Jansson A., Lofgren I., Lundgren K., and Gyltoft K., Bond of reinforcement in selfcompacting steel-fibre-reinforcement concrete. Magazine of Concrete Research, Vol. 64, No.7, 2012, pp.617-630.

[2] Iqbal S.A., Ali K., Holschemacher, and Bier T.A., Mechanical properties of steel fiber reinforced high strength lightweight selfcompacting concrete (shlscc). Construction and Building Materials, Vol. 98, 2015, pp.325333.

[3] Fauzan, Kurniawan R., Fitrah N.O., Lovina A. N., C, and Al Jauhari, Z., Experimental study on the effect of steel fiber waste tyre on high strength concrete. International Journal of GEOMATE, Vol. 16, Issue 58, 2019, pp. 1419.

[4] Antonius, Strength and energy absorption of high-strength steel fiber concrete confined by circular hoops. International Journal of
Technology, Vol.6, Issue 2, 2015, pp.217-226.

[5] Zghair L.A.G., Behavior of plain and high performance polypropylene fiber concrete subjected to elevated temperatures. Eng. and Tech. Journal, Vol. 29, 2011, pp.1517-1535.

[6] Manoharan S.V., and Anandan S., Steel fibre reinforcing characteristics on the size reduction of fly ash based concrete. Advances in Civil Engineering, Vol. 2014, 2014, Article ID 217473, 11 pages.

[7] Zhao M., Zhang B., Shang P., Fu Y., Zhang X., and Zhao S., Complete stress-strain curves of self-compacting steel fiber reinforced expanded-shale lightweight concrete under uniaxial compression. Materials, MDPI, Vol. 12, 2979, 2019, doi:10.3390/ma12182979.

[8] Lam N.N., and Hung L.V., Mechanical and shrinkage behavior of basalt fiber reinforced ultra-high-performance concrete. International Journal of GEOMATE, Vol. 20, Issue 78, 2021, pp.28-35.

[9] Lee S-C., Oh J-H., and Cho J-Y., Compressive behavior of fiber-reinforced concrete with end-hooked steel fibers. Materials (Basel), Vol.8, Issue 4, 2015, pp.1442-1458.

[10] Han A.L., Antonius, and Okiyarta A.W., Experimental study of steel fiber reinforced concrete beams with confinement. Procedia Engineering, Vol. 125, 2015, pp. 1030-1035.

[11] Dhinakaran G., Vijayarakhavan S., Kumar K.R., Fracture and flexural behavior of highperformance fiber reinforced concrete. Asian Journal of Civil Engineering, Vol. 17, No.1, 2016, pp.1-14.

[12] Aslani F., and Bastami M., Constitutive relationships for normal- and high-strength concrete at elevated temperatures. ACI Materials Journal, Vol. 108, No.4, 2011, pp. 355-364.

[13] Kodur V., Properties of concrete at elevated temperatures. ISRN Civil Engineering, Vol. 2014, Article ID 468510, https://doi.org/10.1155/2014/468510.

[14] CEB-FIP, Model code 2010. First Complete Draft Volume 2, pp.108-128.

[15] Antonius, Widhianto A., Darmayadi D., and Asfari G.D., Fire resistance of normal and high-strength concrete with contains of steel fibre. Asian Journal of Civil Engineering, Vol. 15, Issue 5, 2014. pp. 655-669.

[16] Purwanto, Antonius, and Setiyawan P., Evaluation on the mechanical properties of steel fiber-concrete at elevated temperatures. IOP Conference Series: Materials Science and Engineering, Vol. 620, 2019, doi:10.1088/1757-899X/620/1/012025.

[17] Bezerra A.C.S., Maciel P.S., Corrêa E.C.S., Junior P.R.R.S., Aguilar M.T.P., and Cetlin P.R., Effect of high temperature on the 
mechanical properties of steel fiber-reinforced concrete. Fibers, Vol.7, Issue 12, 2019.

[18] Chen H-J., Yu Y-L., and Tang C-W., Mechanical properties of ultra-high performance concrete before and after exposure to high temperatures. Materials, MDPI, Vol.13, Issue 3, 2020.

[19] Blesak L., Goremikins V., Wald F., and Sajdlova T., Constitutive model of steel fibre reinforced concrete subjected to high temperatures. Acta Polytechnica, Vol. 56, Issue 6, 2016, pp. 417-424.

[20] Zhang P., Kang L., Wang J., Guo J., Hu S., and Ling, Y., Mechanical properties and explosive spalling behavior of steel-fiber-reinforced concrete exposed to high temperature-a review. Applied Sciences, MDPI, Vol.10, Issue 7, 2020.

[21] Zaidi K.A., Sharma U.K., and Bhandari N.M., Effect of temperature on uniaxial compressive behavior of confined concrete. Fire Safety Journal, Vol. 48, 2012, pp.58-68.

[22] Korsun V., Vatin N., Franchic A., Korsunb A., Crespic P., and Mashtaler, S., The strength and strain of high-strength concrete elements with confinement and steel fiber reinforcement including the conditions of the effect of elevated temperatures. Procedia Engineering, Vol. 117, 2015, pp.970 - 979.

[23] Antonius, Purwanto, and Harprastanti P., Experimental study of the flexural strength and ductility of post burned steel fiber rc beams. International Journal of Technology, Vol.10, Issue 2, 2019, pp. 428-437.

[24] Kim S., Oli T., and Park, C., Effect of exposure to high temperature on the mechanical properties of SIFRCCs. Applied Sciences, MDPI, Vol.10, Issue 6, 2020.

[25] Araujo, D. de Lima, Nunes, F.G.T., Filho, R.D.T., and Andrade, M.A.S., Shear strength of steel fiber-reinforced concrete beams. Acta Scientiarum, Vol. 36, Issue 3, 2014, pp. 389397.

[26] Gomes, L.D. dos Santos, Oliveira D.R.C., Neto B.N. de Moraes, Medeiros A.B., Macedo A.N., and Silva F.A.C., Experimental analysis of the efficiency of steel fibers on shear strength of beams. Latin American Journal of
Solids and Structures, Vol. 15, Issue 7, 2018, pp. 1-16.

[27] Antonius, Karlinasari R., Purwanto, and Widhianto A., Shear strength and deformation of steel fiber reinforced concrete beams after fire. Advances in Concrete Construction, Vol.10, Issue 2, 2020, pp.105-111.

[28] Cheng F-P, Kodur V.K.R., Wang T-C. Stressstrain curves for high-strength concrete at elevated temperatures. Journal of Materials in Civil Engineering, Vol. 6, 2004, pp. 84-94.

[29] Santos S.O., Rodrigues J.P.C., Toledo R., and Velasco R.V., Compressive behaviour at high temperatures of fibre reinforced concretes. Acta Polytechnica, Vol. 49, 2009, pp.29-33.

[30] Indonesian National Standard, SNI 2847-2019. Requirements of Structural Concrete for Buildings (in Indonesian).

[31] Indonesian National Standard, SNI 7656:2012. Procedures of Mixed Selection for Normal Concrete, Heavy Concrete and Mass Concrete (in Indonesian).

[32] ASTM C 39-94, Test Method for Compressive Strength of Cylindrical Concrete Specimens. Annual Books of ASTM Standards 1996. USA.

[33] ASTM E 119-00a, Standard Test Methods for Fire Tests of Building Construction and Materials

[34] Aoude, H., Hosinieh, M.M., Cook, W.D., and Mitchell, D., Behavior of rectangular columns constructed with scc and steel fibers. Journal of Structural Engineering, Vol. 141, Issue 8, 2015.

[35] Junior et al., Stress-strain curves for steel fiber-reinforced concrete in compression. Revista Materia, Vol.15, Issue 2, 2010, pp. 260-266.

[36] Nataraja M.C., Dhang N., and Gupta A.P., Stress-strain curves for steel-fiber reinforced concrete under compression. Cement \& Concrete Composites, Vol. 21, 1999, pp.383390 .

Copyright (C) Int. J. of GEOMATE All rights reserved, including making copies unless permission is obtained from the copyright proprietors. 